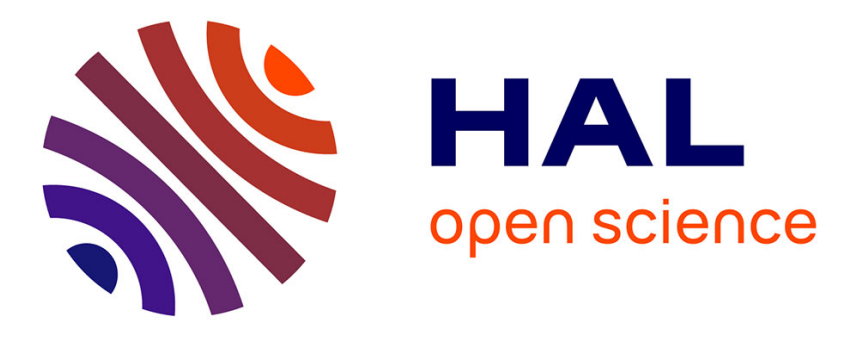

\title{
Secukinumab and ustekinumab treatment in psoriatic arthritis: results of a direct comparison
}

Jean-Guillaume Letarouilly, Benoît Flachaire, Céline Labadie, Maéva Kyheng,

Nicolas Cohen, Jérémie Sellam, Pascal Richette, Philippe Dieude, Pascal

Claudepierre, Bruno Fautrel, et al.

\section{To cite this version:}

Jean-Guillaume Letarouilly, Benoît Flachaire, Céline Labadie, Maéva Kyheng, Nicolas Cohen, et al. Secukinumab and ustekinumab treatment in psoriatic arthritis: results of a direct comparison. Rheumatology, 2021, 60 (6), pp.2773-2782. 10.1093/rheumatology/keaa710 . hal-03176959

\section{HAL Id: hal-03176959 \\ https://hal.science/hal-03176959}

Submitted on 15 Apr 2021

HAL is a multi-disciplinary open access archive for the deposit and dissemination of scientific research documents, whether they are published or not. The documents may come from teaching and research institutions in France or abroad, or from public or private research centers.
L'archive ouverte pluridisciplinaire HAL, est destinée au dépôt et à la diffusion de documents scientifiques de niveau recherche, publiés ou non, émanant des établissements d'enseignement et de recherche français ou étrangers, des laboratoires publics ou privés. 


\title{
Secukinumab and ustekinumab treatment in psoriatic arthritis: results of a direct comparison
}

\author{
Jean-Guillaume Letarouilly (1) ${ }^{1}$, Benoît Flachaire ${ }^{2}$, Céline Labadie ${ }^{3}$, \\ Maéva Kyheng ${ }^{4,5}$, Nicolas Cohen ${ }^{2}$, Jérémie Sellam ${ }^{6}$, Pascal Richette ${ }^{7,8}$, \\ Philippe Dieude ${ }^{9}$, Pascal Claudepierre ${ }^{10,11}$, Bruno Fautrel ${ }^{12}$, \\ Eric Houvenagel ${ }^{13}$, Chi Duc Nguyen ${ }^{14}$, Marie-Hélène Guyot ${ }^{15}$, \\ Nicolas Segaud ${ }^{16}$, Laurent Marguerie ${ }^{17}$, Xavier Deprez ${ }^{18}$, \\ Jean-Hugues Salmon ${ }^{19}$, Guy Baudens ${ }^{20}$, Corinne Miceli-Richard ${ }^{21}$, \\ Elisabeth Gervais ${ }^{22}$, Isabelle Chary-Valckenaere ${ }^{23}$, Pierre Lafforgue ${ }^{2}$, \\ Peggy Philippe $^{1}$, Damien Loeuille ${ }^{22}$, Christophe Richez ${ }^{3}$, Florence Tubach ${ }^{24}$, \\ Thao Pham ${ }^{2}$ and René-Marc Flipo ${ }^{1}$
}

\begin{abstract}
Objectives. To evaluate the characteristics of patients (pts) with PsA treated by ustekinumab (UST) or secukinumab (SEK) and to compare real-world persistence of UST and SEK in PsA.

Methods. In this retrospective, national, multicentre cohort study, pts with PSA (CASPAR criteria or diagnosis confirmed by the rheumatologist) initiating UST or SEK with a follow-up $\geq 6$ months were included from January 2011 to April 2019. The persistence between SEK and UST was assessed after considering the potential confounding factors by using pre-specified propensity-score methods. Causes of discontinuation and tolerance were also collected.

Results. A total of 406 pts were included: 245 with UST and 161 with SEK. The persistence rate was lower in the UST group compared with the SEK group [median persistence 9.4 vs 14.7 months; $26.4 \%$ vs $38.0 \%$ at 2 years; weighted hazard ratio $(\mathrm{HR})=1.42 ; 95 \% \mathrm{Cl}: 1.07,1.92 ; P=0.015]$. In subgroup analysis, the persistence rate of SEK associated with MTX was significantly higher than that of UST associated with MTX: $\mathrm{HR}=2.20 ; 95 \% \mathrm{Cl}$ : 1.30 , 3.51; $P=0.001$, in contrast to SEK vs UST monotherapy: $\mathrm{HR}=1.06 ; 95 \% \mathrm{Cl}$ : $0.74,1.53 ; P=0.75$. Discontinuation due to inefficacy was reported in $91.7 \%$ (SEK) and $82.4 \%$ (UST) of pts. Discontinuation due to an adverse event was reported in $12.2 \%$ (SEK) and $7.7 \%$ (UST) of pts.

Conclusion. In this first study comparing UST and SEK, the persistence of SEK was higher than that of UST in PsA. In subgroup analysis, this difference was only found in association with MTX.
\end{abstract}

Key words: psoriatic arthritis, real-world, ustekinumab, secukinumab, persistence

\footnotetext{
${ }^{1}$ Service de Rhumatologie, Université Lille, CHU Lille, Lille, ${ }^{2}$ Service de Rhumatologie, Univ. Aix-Marseille, APHM, Marseille, ${ }^{3}$ Service de Rhumatologie, Université Bordeaux, CHU Bordeaux, Bordeaux, ${ }^{4}$ ULR 2694 - METRICS: Évaluation des Technologies de santé et Des Pratiques Médicales, Université Lille, ${ }^{5}$ Département des Biostatistiques, CHU de Lille, Lille, France, ${ }^{6}$ Service de Rhumatologie, APHP, Hôpital Saint Antoine, Sorbonne Université, CRSA Inserm UMRS_938, 7 Service de Rhumatologie, APHP, Hôpital Lariboisière, ${ }^{\overline{8}}$ Inserm, UMR-S 1132, Bioscar, Université de Paris, ${ }^{9}$ Service de Rhumatologie, Université de Paris, INSERM UMR1152, Groupe Hospitalier Universitaire Bichat-Claude Bernard, APHP, Paris, ${ }^{10} \mathrm{Ep}$, iDermE, EA7379, Université Paris Est Creteil,

${ }^{11}$ Department of Rheumatology, Hopital Henri-Mondor, AP-HP, Creteil, ${ }^{12}$ Service de Rhumatologie, Hôpital Pitié, Sorbonne Université, AP-HP, Paris, ${ }^{13}$ Service de Rhumatologie, Institut Catholique de Lille, Hôpital Saint Philibert, Ghicl, Lomme, ${ }^{14}$ Service de Rhumatologie, $\mathrm{CH}$ Béthune, Beuvry, ${ }^{15}$ Service de Rhumatologie,
}

CH Roubaix, Roubaix, ${ }^{16}$ Service de Médecine Interne, $\mathrm{CH}$ Armentières, Armentières, ${ }^{17}$ Service de Rhumatologie, Institut Calot, Berck, ${ }^{18}$ Service de Rhumatologie, $\mathrm{CH}$ Valenciennes, Valenciennes, 19 Service de Rhumatologie, Université Reims, ChampagneArdenne, CHU Reims, Reims, ${ }^{20}$ Cabinet, Libéral de Rhumatologie, Valenciennes, ${ }^{21}$ Service de Rhumatologie, Université de Paris, CHU

Cochin, AP-HP, Paris, ${ }^{22}$ Service de Rhumatologie, Université de Poitiers, CHU Poitiers, Poitiers, ${ }^{23}$ Service de Rhumatologie, Université Lorraine, CHU Nancy, Nancy, and ${ }^{24}$ Département de Santé Publique, Centre de Pharmacoépidémiologie (Cephepi), Institut Pierre Louis d'Epidémiologie et de SantéPublique, Hôpital ce Submitted 26 June 2020; accepted 19 September 2020

Correspondence to: Jean-Guillaume Letarouilly, CHU Lille, 2, Avenue Oscar Lambret, 59037 Lille Cedex, France. E-mail: jeanguillaume. letarouilly@gmail.com 
- There is no head-to-head study comparing IL17 inhibitors and IL23 inhibitors in PsA.

- The persistence of secukinumab was superior to the persistence of ustekinumab in PsA patients.

- The superiority of secukinumab over ustekinumab was statistically significant in the combination with the methotrexate subgroup.

\section{Introduction}

According to the EULAR recommendations updated in 2020 [1], biological disease-modifying antirheumatic drugs (bDMARDs) should be initiated in patients with active peripheral PSA and an inadequate response to conventional synthetic disease-modifying antirheumatic drugs (csDMARDs). For $>20$ years, TNF inhibitors (TNFi), the only available drug class, have provided an effective solution after failure of a csDMARD [2]. However, a substantial number of patients with PsA experience inadequate response or contraindication to TNFi [3]. Two fully humanized monoclonal antibodies have been developed to propose a therapeutic alternative to these patients [4]. Ustekinumab (UST) targets the p40 subunit shared by the interleukins IL-12 and IL-23 [5], whereas secukinumab (SEK) blocks interleukin 17 A [6]. According to the new EULAR recommendations, SEK and UST should be preferred in patients with relevant skin involvement [1].

In France, UST has been available for psoriasis treatment since January 2009 and for PsA since October 2014. SEK has been granted market authorization for PsA since June 2016. They are indicated for the treatment of PsA in patients with active disease despite csDMARD [7] and are subjected to hospital initial prescription.

Randomized clinical trials (RCT) have shown efficacy of these antibodies for the treatment of PsA [8, 9]. Yet, patients included in clinical trials are highly selected and are not broadly representative of patients encountered in daily practice $[10,11]$. Thus, real-world evidence (RWE) is needed [12]. There are few RWE studies of UST [13-18] and SEK [19, 20]. Most real-world studies were carried out on a small number of patients $(<100)$, limiting the external validity of these studies. Moreover, there are no head-to-head studies comparing UST and SEK in PsA, only two head-to-head trials comparing IL17 inhibitors and TNFi [21, 22] .

The objectives of this retrospective multicentric realworld study were to determine the characteristics of patients treated in usual practice with UST and SEK, to assess and compare the persistence of these two bDMARDs in PsA. Safety data were also collected.

\section{Methods}

Study design and participants

A retrospective, national, multicentre (18 centres) cohort study was conducted. Patients were identified by
International Classification of Diseases-10 diagnostic code (L40.5 and M07.0-3) thanks to the departments of medical informatics of 10 hospitals. Three departments of rheumatology had a registry of PsA patients treated with bDMARDs. In both cases, data were extracted from patients' medical files. Finally, six departments already had an electronic database based on the patients' medical files with all the information needed for this study. Patients with PsA were included if they fulfilled the Classification Criteria for Psoriatic Arthritis (CASPAR) criteria or with a diagnosis of PSA confirmed by a rheumatologist, and if they initiated UST or SEK between January 2011 to January 2019 with a follow-up $\geq 6$ months regardless of whether the treatment was further discontinued or not. Patients who may have died before the 6-month follow-up were included. Initiation of UST or SEK was the index date.

Demographic and clinical data at index date were collected including age, sex, BMI, smoking status, psoriasis, pattern of involvement of PsA (axial, peripheral or axial and peripheral), duration of PsA, previous and current csDMARDs and bDMARDs especially the combination with a csDMARD.

\section{Outcome measure}

The primary end point was the persistence of UST and SEK at 2 years defined as the time from initiation to discontinuation. In patients who switched from UST to SEK or from SEK to UST, only the first bDMARD was assessed for treatment persistence. Subjects still under treatment at the end of the observation period were censored at the date of the last visit during the observation period. A secondary end point was the persistence of UST and SEK at 1 year. Reasons of discontinuation were collected (primary inefficacy, secondary inefficacy, adverse events, remission and other reasons such as pregnancy). Primary inefficacy was defined as an inadequate response to treatment (i.e. increase or stable number of swollen joints and tender joints based on the $66 / 68$ joint count and/or stable or deterioration of the physician's global assessment and/or stable or deterioration of psoriasis) within the six-month period after initiation. Secondary inefficacy was defined as a loss of response to treatment (i.e. increase or stable number of swollen joints and tender joints and/or stable or deterioration of the physician's global assessment and/or stable or deterioration of psoriasis) after an initial six-month response. 


\section{Statistical analysis}

Continuous variables are expressed as means (s.D.) in the case of normal distribution or medians (interquartile range, IQR) otherwise. Categorical variables are expressed as numbers (percentage). Persistence was estimated using the Kaplan-Meier method, persistence rates at 2 years were reported. Baseline characteristics were described according to the treatment SEK and UST and the magnitude of the between-group differences were assessed by calculating the absolute standardized difference; an absolute standardized difference $>10 \%$ was interpreted as a clinically relevant difference [23].

The persistence of SEK and UST was assessed accounting for the potential confounding factors by using propensity score matching method (propensity score was used to assemble well-balanced groups) as primary analysis, and by using inverse probability of treatment weighting (IPTW) propensity score method (using stabilized inverse propensity score as weighty in regression models) as secondary analysis. The propensity score was estimated using a non-parsimonious multivariable logistic regression model, with the treatment group as the dependent variable and all of the characteristics listed in Table 1 as covariates. To evaluate bias reduction using the propensity score matching method, absolute standardized differences (ASD) were calculated (Supplementary Fig. 1, available at Rheumatology online). Patients from the UST group were matched 1:1 to patients in the SEK group according to propensity score using the greedy nearest neighbour matching algorithm with a calliper width of 0.2 (S.D.) of logit of propensity score [24].

Because of missing baseline data, the treatment effect size in propensity score, IPTW and matched cohorts was estimated after handling missing covariate values by multiple imputation [25] using a regression switching approach (chained equations with $m=10$ ). Imputation procedure was performed under the missing at random assumption using all variables listed in Table 1 (including treatment group) with a predictive mean matching method for continuous variables and multinomial or binary logistic regression model for categorical variables. In each imputed dataset, the propensity score and the weight of IPTW were calculated and a matched cohort was assembled to provide both weighted-adjusted and matched effect sizes. Therefore, effect sizes from each imputed dataset using Rubin's rules were combined [26].

In the IPTW cohort, the persistence of SEK and UST were compared by using Cox's regression models with use of stabilized inverse propensity score as weight. In the propensity-score matched cohort, comparisons were done using Cox's regression models with robust sandwich variance estimator to account for the matched design. Two sensitivity analyses have been performed to assess and compare persistence of SEK and UST firstly in the population without patients treated by UST before the launch of SEK (to prevent bias when only UST was available) and secondly in the population without patients

TABLE 1 Baseline characteristics according molecules before and after propensity score-matching

\begin{tabular}{|c|c|c|c|c|c|c|}
\hline \multirow[b]{2}{*}{ Characteristics } & \multicolumn{3}{|c|}{ Before propensity-score matching } & \multicolumn{3}{|c|}{ After propensity-score matching ${ }^{\mathbf{b}}$} \\
\hline & $\begin{array}{c}\text { Secukinumab } \\
\quad(n=161)\end{array}$ & $\begin{array}{l}\text { Ustekinumab } \\
\quad(n=245)\end{array}$ & $\begin{array}{c}\text { ASD, } \\
\%\end{array}$ & $\begin{array}{l}\text { Secukinumab } \\
\quad(n=136)\end{array}$ & $\begin{array}{c}\text { Ustekinumab } \\
(n=136)\end{array}$ & $\begin{array}{c}\text { ASD, } \\
\%\end{array}$ \\
\hline Women & $97(60.2)$ & $143(58.4)$ & 3.8 & $80(58.5)$ & $82(60.4)$ & 4.5 \\
\hline Age (years), mean (s.D.) & $49.0(12.7)$ & $49.9(10.9)$ & 7.2 & $49.1(12.8)$ & $49.0(12.8)$ & 5.3 \\
\hline BMI $\left(\mathrm{kg} / \mathrm{m}^{2}\right)$, mean (S.D.) & $27.1(6.3)$ & $28.3(7.8)$ & 20.2 & $27.2(7.0)$ & $27.0(8.2)$ & 6.3 \\
\hline Duration of disease (years), median (IQR) & $7.0(3.0-13.0)$ & $8.0(3.0-14.0)$ & $6.8^{\mathrm{a}}$ & $7.0(3.0-13.0)$ & $8.0(3.0-14.0)$ & $6.8^{2}$ \\
\hline Peripheral involvement & $77(48.1)$ & $130(52.9)$ & 10.6 & $62(45.3)$ & $62(45.8)$ & 5.8 \\
\hline CASPAR criteria & $114(70.8)$ & $181(73.9)$ & 6.7 & $101(74.1)$ & $100(73.4)$ & 3.2 \\
\hline \multicolumn{7}{|l|}{ Smoking status } \\
\hline Non-smoker & $72(44.9)$ & $119(48.6)$ & 17.6 & $65(48.2)$ & $66(48.7)$ & 7.5 \\
\hline Former smoker & $45(28.0)$ & 77 (31.5) & & 37 (27.2) & $37(27.5)$ & \\
\hline Current smoker & $44(27.1)$ & 49 (19.9) & & $34(24.6)$ & $33(23.7)$ & \\
\hline Cutaneous psoriasis & $134(83.2)$ & $236(96.3)$ & 44.5 & $127(93.4)$ & $127(93.5)$ & 6.8 \\
\hline Combination with MTX & $71(44.2)$ & 95 (38.9) & 10.8 & $59(43.1)$ & $60(44.2)$ & 4.1 \\
\hline $\mathrm{CRP}>5 \mathrm{mg} / \mathrm{l}$ & $76(47.0)$ & $133(54.3)$ & 14.6 & $67(49.4)$ & $68(49.8)$ & 5.3 \\
\hline 0 prior bDMARD & $21(13.0)$ & $54(22.0)$ & $30.3^{a}$ & $17(12.5)$ & $17(12.7)$ & $3.1^{\mathrm{a}}$ \\
\hline 1 prior bDMARD & $37(23.0)$ & $68(27.8)$ & & $30(22.0)$ & $31(23.0)$ & \\
\hline 2 prior bDMARDs & $43(26.7)$ & $57(23.3)$ & & $37(27.1)$ & $36(26.5)$ & \\
\hline$\geq 3$ prior bDMARDs & $60(37.3)$ & $66(26.9)$ & & $52(38.3)$ & $52(37.7)$ & \\
\hline
\end{tabular}

Values are expressed as number (\%) unless otherwise indicated. Values were calculated after handling missing data using

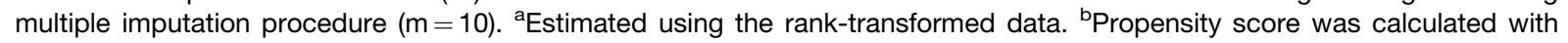
all parameters in Table1. ASD: absolute standardized difference; CASPAR: classification criteria for PsA; IQR: interquartile range. 
who switched from UST to SEK or SEK to UST (Supplementary Figs 2 and 3, available at Rheumatology online).

In the overall population, sensitivity analysis were further run to investigate the heterogeneity in treatment effect size for persistence in different subgroups: age $(\leq 65$, $>65)$, sex, BMl $(<25,25-29, \geq 30)$, Charlson comorbidity index $(\leq 2,>2)$, cutaneous psoriasis, high CRP defined as $>5 \mathrm{mg} / \mathrm{l}$, prior bDMARD $(0,1,2, \geq 3)$, maximum dosage (90 mg every 12 weeks for UST and $300 \mathrm{mg}$ every 4 weeks for SEK), combination with MTX, enthesitis, axial involvement and swollen joints at treatment initiation by introducing a multiplicative term into regression models, both in IPTW and propensity-score-matched cohorts. Statistical testing was conducted at the two-tailed $\alpha$-level of 0.05. Data were analysed using the SAS software version 9.4 (SAS Institute, Cary, NC, USA).

\section{Ethical considerations}

As a retrospective study, an Ethics Committee and Institutional Review Board and informed consent from patients were not required. The study was registered with the French data protection agency, Commission nationale de l'informatique et des libertés (CNIL) (DECT number 16-172).

\section{Results}

\section{Study population}

A total of 406 patients with PsA were included between January 2011 and January 2019: 161 with SEK and 245 with UST. Some patients treated with UST were included before October 2014 because they presented a severe psoriasis with an indication for UST. In total, 136 of 406 patients matched pairs (mean value of 10 imputed dataset) for the propensity-score matching method. Table 1 shows the baseline characteristics after handling missing values by multiple imputations according to the two study groups before and after propensity score-matching (Supplementary Table 1, available at Rheumatology online, and Fig. 1 for baseline characteristics before matching and handling missing values). Considering meaningful differences defined as absolute standard differences $>10 \%$, the UST group was not different from the SEK group on baseline characteristics after propensity score-matching. Age range was from 18 to 75 years old for UST and from 19 to 81 years old for SEK. BMI range was from 15.6-50.4 for both UST and SEK. A few patients were naïve to bDMARD $(22 \%$ and $13 \%$, respectively for UST and SEK). UST was prescribed with the recommended dosage in 214/220 patients $(97.3 \%)$, i.e. $45 \mathrm{mg}$ every 12 weeks for patients weighing less than or equal to $100 \mathrm{~kg}$ and $90 \mathrm{mg}$ every 12 weeks for patients weighing $>100 \mathrm{~kg}$. SEK was prescribed with the dosing scheme of $150 \mathrm{mg}$ every 4 weeks in $78 / 159$ patients (49\%) and with the dosing scheme of $300 \mathrm{mg}$ every 4 weeks in 81 patients $(51 \%)$. SEK was prescribed with the recommended dosage in $96 / 159$ patients $(60.4 \%)$, i.e. $150 \mathrm{mg}$ every 4 weeks if the patient is naïve to bDMARD and $300 \mathrm{mg}$ every 4 weeks if the patient has an inadequate response to TNF inhibitors or if the patient is naïve to bDMARD but presents a severe plaque psoriasis. SEK was prescribed

FIG. 1 Persistence with ustekinumab (UST) and secukinumab (SEK) in IPTW cohort

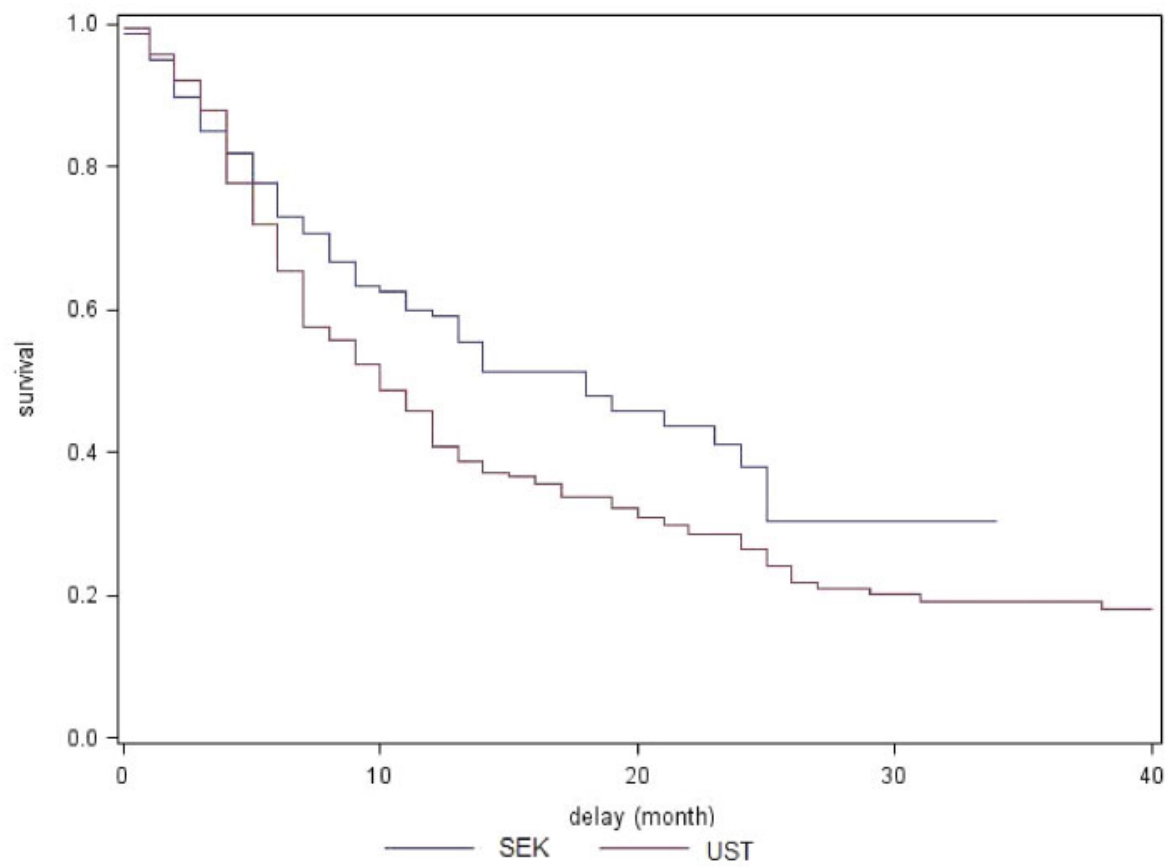

HR: hazard ratio; IPTW: inverse probability of treatment weighting. 
at a lower dosage than recommended in the other patients.

\section{Persistence of ustekinumab and secukinumab}

The median persistence for UST was 9.4 months and for SEK 14.7 months (Fig. 1). In the propensity-score matched analysis, the persistence was lower in the UST group compared with the SEK group: persistence rate at 1 year was $40.9 \%$ vs $59.1 \%$; at 2 years $25.5 \%$ vs $36.9 \%$; hazard ratio $(\mathrm{HR})=1.42$; $95 \% \mathrm{Cl}: 1.02,2.00$ for both times. Similar differences were found in the IPTW analysis $(26.4 \%$ vs 38.0 at 2 years; $\mathrm{HR}=1.42 ; 95 \% \mathrm{Cl}$ : $1.07,1.92)$. Similar between-group difference was found in sensitivity analyses, although the difference reached the significance level only in IPTW analysis restricted to patients without those treated by UST before the launch of SEK (17.5\% vs $39.0 \%$ at 2 years; $\mathrm{HR}=1.51 ; 95 \% \mathrm{Cl}$ : $1.05,2.17$ ) (Table 2). One hundred and eighty of 245 patients discontinued UST because of primary inefficacy in $127 / 180$ patients $(70.6 \%)$, secondary inefficacy in $38 / 180$ patients $(21.1 \%)$, an adverse event in $14 / 180$ patients $(7.7 \%)$ and other causes (remission) in $3 / 180$ patients (1.6\%) (Supplementary Table 1, available at Rheumatology online). Primary inefficacy was mostly related to joint response. It was related to skin and joint response in three patients. Secondary inefficacy was only related to joint response. Adverse events leading to discontinuation included infection in $4 / 14$ patients (28.6\%), allergy in $1 / 14$ patients $(7.1 \%)$, cutaneous vasculitis in $3 / 14$ patients $(21.5 \%)$, cancer in $2 / 14$ patients $(14.4 \%)$, chest pain in $1 / 14$ patients $(7.1 \%)$, suicidal ideation in $1 / 14$ patients $(7.1 \%)$, abdominal pain in $1 / 14$ patients $(7.1 \%)$ and diarrhoea in $1 / 14$ patients $(7.1 \%)$. Seventy-four of 161 patients discontinued SEK because of primary inefficacy in $45 / 74$ patients $(60.8 \%)$, secondary inefficacy in $16 / 74$ patients $(21.6 \%)$, an adverse event in 9/74 patients (12.2\%) and other causes (surgery and pregnancy) in $4 / 74$ patients (5.4\%) (Supplementary Table 1, available at Rheumatology online). Primary inefficacy was mostly related to joint response. It was related to skin and joint response in one patient. It was related to skin response in two patients. Secondary inefficacy was only related to joint response. Adverse events leading to discontinuation included infection in 5/ 9 patients (55.6\%), allergy in $1 / 9$ patients (11.1\%), cough in $1 / 9$ patients $(11.1 \%)$, pruritus in $1 / 9$ patients (11.1\%), headache in $1 / 9$ patients $(11.1 \%)$. One patient who switched from UST to SEK presented new onset Crohn's disease.

\section{Subgroup analysis}

Among the subgroups tested, heterogeneity in effect size was found in the difference in the persistence of SEK and UST according MTX association or not, in both matched and IPTW analyses, although the heterogeneity test did not reach the significance level in matched analysis ( $P=0.075$, Figs 2 and 3 ). The higher persistence of SEK compared with UST was only found in patients cotreated with MTX, with a HR $2.07(95 \% \mathrm{Cl}: 1.20,3.57)$ in matched analysis and $2.20(95 \% \mathrm{Cl}: 1.30,3.51)$ in IPWT analysis. In patients without MTX, the corresponding HR were 1.06 (95\% Cl: $0.67,1.67)$ and 1.06 (95\% Cl: 0.74 , 1.53), respectively.

In UST-MTX, the causes of discontinuation were due to primary inefficacy in $42 / 60$ patients $(70 \%)$, to secondary inefficacy in $14 / 60$ patients $(23.3 \%)$ and an adverse event in $4 / 60$ patients $(6.7 \%)$. In SEK-MTX, the causes of discontinuation were due to primary inefficacy in $14 /$ 29 patients $(48.3 \%)$, to secondary inefficacy in $10 / 29$ patients $(34.5 \%)$, an adverse event in $2 / 29$ patients $(6.9 \%)$ and other causes (surgery and pregnancy) in $3 /$ 29 patients (10.3). In UST monotherapy, an adverse

TABLE 2 Follow-up 2-year persistence of molecules in propensity-score matched and IPTW cohorts

\begin{tabular}{|c|c|c|c|c|c|c|}
\hline & $n$ & Ustekinumab & $n$ & Secukinumab & HR $(95 \% \mathrm{Cl})$ & P-value \\
\hline \multicolumn{7}{|l|}{ Main analysis } \\
\hline Propensity score matched & 136 & $92(25.5)$ & 136 & $60(36.9)$ & $1.42(1.02,2.00)^{\mathrm{C}}$ & 0.036 \\
\hline IPTW & 161 & $161(26.4)$ & 245 & $70(38.0)$ & $1.42(1.07,1.92)^{d}$ & 0.015 \\
\hline \multicolumn{7}{|l|}{ Sensitivity analysis $1^{\mathrm{a}}$} \\
\hline Propensity score matched & 89 & $61(12.2)$ & 89 & $39(40.5)$ & $1.47(0.93,2.32)^{\mathrm{c}}$ & 0.091 \\
\hline IPTW & 158 & $91(17.5)$ & 138 & 68 (39.0) & $1.51(1.05,2.17)^{d}$ & 0.024 \\
\hline \multicolumn{7}{|l|}{ Sensitivity analysis $2^{\mathrm{b}}$} \\
\hline Propensity score matched & 121 & $72(32.4)$ & 121 & 47 (41.3) & $1.33(0.92,1.92)^{\mathrm{C}}$ & 0.13 \\
\hline IPTW & 149 & $106(32.7)$ & 183 & $58(42.1)$ & $1.35(0.96,1.92)^{d}$ & 0.085 \\
\hline
\end{tabular}

\footnotetext{
${ }^{a}$ Analysis in population without patients treated by ustekinumab before the launch of secukinumab. ${ }^{b}$ Analysis without patients who switched from ustekinumab to secukinumab or secukinumab to ustekinumab. Values in columns 3 and 5 are number of molecules stops and molecule persistence rate (in brackets) at 2-year expresses as \% (calculated using Kaplan-Meier method). ${ }^{\circ}$ Calculated using Cox's regression model with the robust sandwich variance estimate to account the matched sets. 'Calculated using a Cox's regression with an inverse probability of treatment weighting (IPTW) propensity score. Number of events, persistence rate and HRs were calculated after handling missing values for all baseline variables (Supplementary Table S1, available at Rheumatology online) by multiple imputation. HR: hazard ratio.
} 
FIG. 2 Follow-up 2-year persistence of UST and SEK according to different subgroups in IPTW Cohorts

\begin{tabular}{|c|c|c|c|c|c|c|}
\hline Subgroups & $\begin{array}{c}\text { Ustekinumab } \\
n-245\end{array}$ & $\begin{array}{c}\text { Secukinumab } \\
n-161\end{array}$ & HR $(95 \% C 1)^{2}$ & & $P$-value & P-het \\
\hline \multicolumn{7}{|l|}{ Age, year } \\
\hline$\leq 65$ & $150(27.1)$ & $65(36.1)$ & $1.44(1.05$ to 1.97$)$ &. & 0.022 & 0.89 \\
\hline$>65$ & $11(11.9)$ & $5(53.3)$ & $1.37(0.68$ to 2.77$)$ & $=$ & 0.38 & \\
\hline \multicolumn{7}{|l|}{ Sexe } \\
\hline Men & $61(34.6)$ & $29(37.6)$ & $1.27(0.79$ to 1.90$)$ & 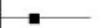 & 0.36 & 0.38 \\
\hline Women & $100(20.6)$ & $41(38.8)$ & 1.59 (1.08 to 2.34$)$ & $\square$ & 0.018 & \\
\hline \multicolumn{7}{|c|}{ Body Mass Index $\left(\mathrm{kg} / \mathrm{m}^{2}\right)$} \\
\hline$<25$ & $57(25.9)$ & $25(48.1)$ & $1.69(0.99$ to 2.90$)$ & & 0.055 & 0.58 \\
\hline $25-29$ & $50(28.1)$ & $24(34.6)$ & $1.24(0.73$ to 2.10$)$ &. & 0.43 & \\
\hline 230 & $54(25.9)$ & $21(30.6)$ & $1.36(0.76$ to 2.44$)$ & 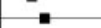 & 0.30 & \\
\hline \multicolumn{7}{|c|}{ Charlson Comorbidity index } \\
\hline$s 2$ & $134(26.5)$ & $55(38.2)$ & $1.47(1.01$ to 2.07$)$ & & 0.029 & 0.7 \\
\hline$>2$ & $27(24.6)$ & $15(37.4)$ & $1.29(0.74$ to 2.24$)$ & - & 0.37 & \\
\hline \multicolumn{7}{|l|}{ Cutaneous Psoriasis } \\
\hline No & $7(21.8)$ & $12(40.2)$ & 2.59 (1.04 to 6.44$)$ & & 0.040 & 0.18 \\
\hline Yes & $154(26.9)$ & $58(38.0)$ & $1.34(0.99$ to 1.82$)$ & - & 0.059 & \\
\hline \multicolumn{7}{|l|}{ High CRP } \\
\hline No & $63(36.2)$ & $38(35.2)$ & $1.15(0.73$ to 1.83$)$ & $=$ & 0.54 & 0.24 \\
\hline Yes & $98(17.8)$ & $32(40.5)$ & $1.72(1.12$ to 2.65$)$ & & 0.013 & \\
\hline O prior BDMARD & $29(32.3)$ & $6(45.9)$ & $1.64(0.79$ to 3.42$)$ & $\because$ & 0.18 & 0.71 \\
\hline 1 prior bDMARD & $48(17.6)$ & $17(49.8)$ & $1.20(0.68$ to 2.12$)$ & & 0.52 & \\
\hline 2 prior BDMARDs & $43(22.4)$ & $19(30.0)$ & $1.29(0.68$ to 2.45$)$ & & 0.43 & \\
\hline 23 prior bDMARDS & $41(31.6)$ & $28(34.9)$ & 1.66 (1.02 to 2.68$)$ & & 0.039 & \\
\hline \multicolumn{7}{|l|}{ Maximum dosage } \\
\hline No & $114(26.2)$ & $35(37.5)$ & $1.30(0.87$ to 1.93$)$ & . & 0.20 & 0.61 \\
\hline Yes & $47(26.0)$ & $35(38.0)$ & 1.51 (0.97 to 2.35$)$ & & 0.066 & \\
\hline \multicolumn{7}{|c|}{ Combination with methotrexate } \\
\hline No & $92(28.4)$ & $43(33.8)$ & $1.06(0.74$ to 1.53$)$ &. & 0.75 & 0.015 \\
\hline Yes & $66(23.2)$ & $27(43.6)$ & $2.20(1.3$ to 3.51$)$ & $\longrightarrow$ & 0.001 & \\
\hline \multicolumn{7}{|l|}{ Enthesitis } \\
\hline No & $121(26.4)$ & $53(40.0)$ & $1.57(1.12$ to 2.21$)$ & 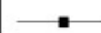 & 0.010 & 0.24 \\
\hline Yes & $40(26.3)$ & $17(\mathrm{NA})$ & 1.06 (0.61 to 1.86$)$ & 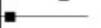 & 0.83 & \\
\hline \multicolumn{7}{|l|}{ Axial involvement } \\
\hline No & $86(27.4)$ & $32(39.7)$ & $1.42(0.93$ to 2.16$)$ & 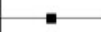 & 0.11 & 0.92 \\
\hline Yes & $75(25.0)$ & $38(40.0)$ & $1.46(0.95$ to 2.25$)$ & - & 0.085 & \\
\hline \multicolumn{7}{|l|}{$\begin{array}{l}\text { Swollen joint(s) at } \\
\text { treatment initiation }\end{array}$} \\
\hline No & $69(29.1)$ & $43(43.4)$ & $1.36(0.91$ to 2.04$)$ & 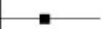 & 0.14 & 0.92 \\
\hline \multirow[t]{3}{*}{ Yes } & $92(24.2)$ & $27(30.0)$ & $1.40(0.88$ to 2.23$)$ & - & 0.15 & \\
\hline & \multirow{2}{*}{\multicolumn{3}{|c|}{0,1}} & 1 & 10 & \\
\hline & & & & \%(C) & & \\
\hline
\end{tabular}

Values in columns 2 and 3 are number of molecules stops and molecule survival rate (in brackets) at 2-year expresses as \% (calculated using Kaplan-Meier method). ${ }^{a}$ Calculated using a Cox's regression with an inverse probability of treatment weighting (IPTW) propensity score. Number of events, persistence rate and HRs were calculated after handling missing values for all baseline variables (Supplementary Table S1, available at Rheumatology online) by multiple imputation using ustekinumab (UST) group as reference. $P$-het indicates $P$-values for heterogeneity in treatment effect sizes across first-line strategy subgroups. HR: hazard ratio; SEK: secukinumab.

event was the cause of discontinuation in $10 / 120$ patients (8.3\%). In SEK monotherapy, an adverse event was the cause of discontinuation in $7 / 44$ patients (15.9\%).

\section{Discussion}

In this retrospective, multicentric, cohort study, the persistence of UST was lower than the persistence of SEK in propensity-score matched and IPTW analysis. The median persistence for UST was 9.4 months and for SEK 14.7 months. A similar difference between groups was found in sensitivity analyses, although the difference reached the significance level only in IPTW analysis restricted to patients treated when by UST after the launch of SEK. It should be noted that there were fewer patients analysed in the propensity-score matched analysis restricted to patients treated after the launch of
SEK compared with the IPTW analysis (178 vs 296) and this could have led to a lack of statistical power. Only the combination with MTX emerged in subgroup analysis.

Over the past few years, alternative drugs to TNF inhibitors in severe PsA have been launched. Yet, most data came from clinical trials in which patients are highly selected. Comparison between drugs are even rarer in PsA [21, 27-29]. RWE are scarce about SEK and UST in PsA. Two studies reported the persistence of UST in PsA $[16,18]$. Azuaga et al. showed a 12-month persistence rate of $64.1 \%$ in 201 Spanish patients with PsA treated with UST. bDMARD-naïve patients and those treated with one prior TNFi had a significantly higher 12month persistence rate than patients treated with two or more prior TNFi. Discontinuation due to inefficacy was the most frequent cause (72.9\%) [18]. Walsh et al. analysed data of patients who initiated therapy with a bDMARD for PsA obtained from the Optum Research 
FIG. 3 Follow-up 2-year persistence of UST and SEK according to different subgroups in propensity-score matched cohorts

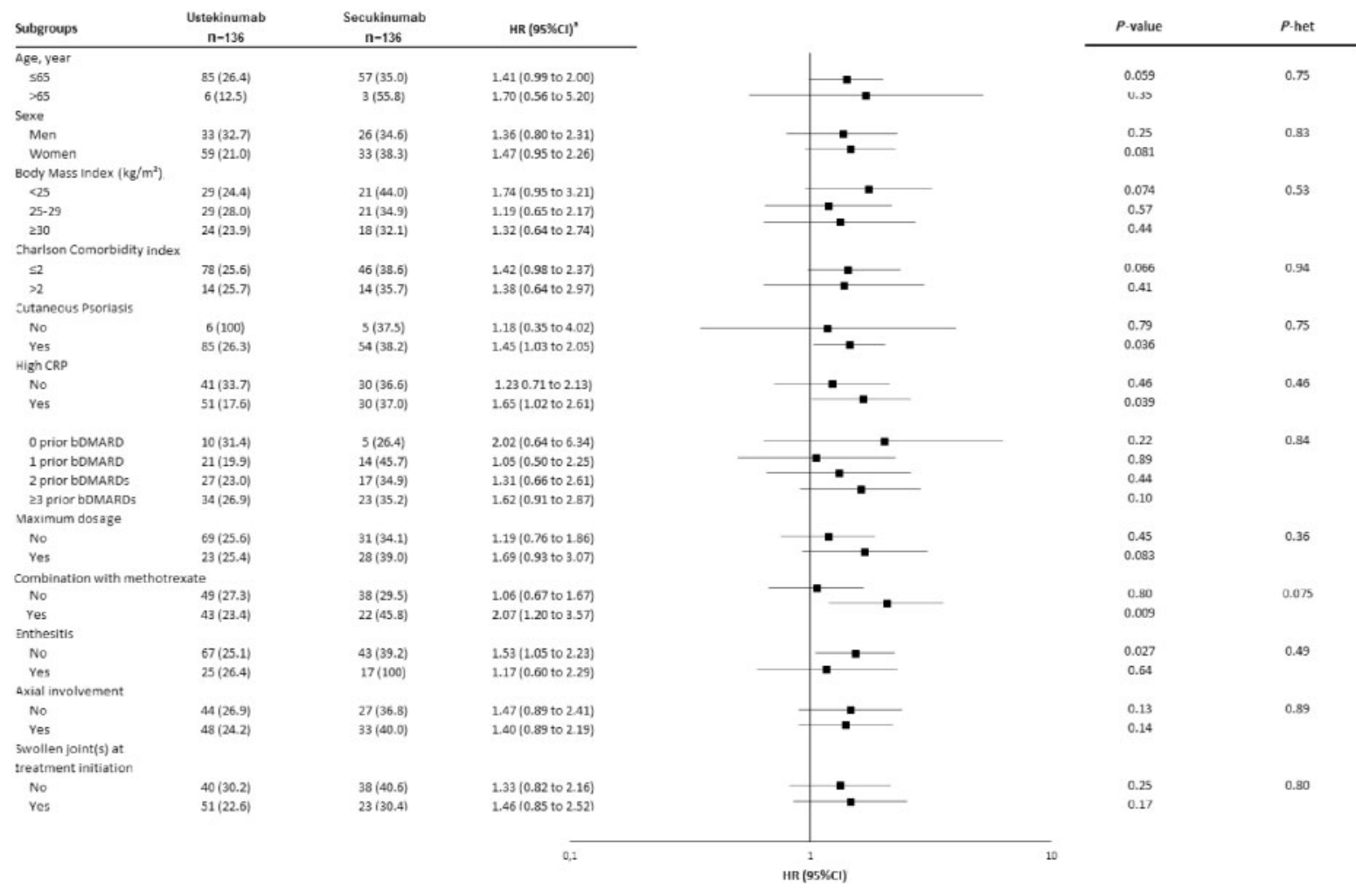

Values in columns 2 and 3 are number of molecules stops and molecule survival rate (in brackets) at 2-year expresses as \% (calculated using Kaplan-Meier method). ${ }^{a}$ Calculated using Cox's regression model with the robust sandwich variance estimate to account the matched sets. Number of events, survival rate and HRs were calculated after handling missing values for all baseline variables (Supplementary Table S1, available at Rheumatology online) by multiple imputation using ustekinumab (UST) group as reference. High CRP defined as CRP $>5 \mathrm{mg} / \mathrm{l}$. $P$-het indicates $P$-values for heterogeneity in treatment effect sizes across first-line strategy subgroups. HR: hazard ratio; SEK: secukinumab.

Database. It includes commercial and Medicare Advantage health plan members. Eighty-nine patients with PsA were treated with UST. The 12-month persistence rate was $50.6 \%$. Most patients were naïve to bDMARDs (81\%) [16]. We found a 12-month retention rate of $40.9 \%$ in our patients treated with UST, but there was a higher number of patients treated with two or more prior TNFi (50.2\%) than in these studies.

Only one study about persistence of SEK in real-world has been published. Pinto Tasende et al. reported a 12month persistence rate of $90.9 \%$ in naïve to bDMARDs and $81.5 \%$ in non-naïve to bDMARDs patients in 76 patients with PSA treated with SEK. A total of 22/76 patients $(28.9 \%)$ were naïve to bDMARDs [19] compared with $21 / 161(13.0 \%)$ in our study. Similar to our study, discontinuation due to primary inefficacy was the most frequent cause $(66.7 \%)$.

The benefit of combining MTX with bDMARDs remains unclear in PsA. Two longitudinal observational studies have suggested that the association MTX-TNF inhibitors was not statistically superior to TNF inhibitor monotherapy in terms of response and persistence [30, 31]. In our study, SEK associated with MTX had a superior persistence compared with UST associated with MTX. It should be noted that there was a higher number of discontinuation due to an adverse event in the SEK monotherapy group compared with SEK-MTX group (15.9\% vs $6.9 \%)$. This could partially explain the statistical superiority of SEK-MTX to UST-MTX in subgroup analysis. However, SEK is associated with a low incidence of immunogenicity in patients with PsA. Deodhar et al. analysed 1414 patients with PsA from the clinical trials (FUTURE 1,2 and 3 ). Only five $(0.35 \%)$ patients developed treatment-emergent antidrug antibodies [32]. There is no published data about immunogenicity in patients with PsA treated with UST.

Concerning safety, these two bDMARDs were well tolerated with a low number of discontinuations due to an adverse event (9/161 patients with SEK and 14/245 with UST), as expected according to clinical trials [8, 9]. There was only one case of new onset Crohn's disease in the SEK group. Yet, UST had a numerically lower 
number of discontinuations due to an adverse event than SEK.

A strength of this study was to compare SEK and UST in a large real-world cohort of patients with PsA. Most of the patients were not eligible for the RCT of UST [8] and SEK [9] for the treatment of PSA. They were also older than those included in these RCTs. To the best of our knowledge, it is the first study to do this direct comparison between two non-TNFi bDMARDs in PsA. There are no head-to-head trials comparing UST and SEK in PSA. There are only head-to-head trials comparing IL-17 inhibitors to adalimumab (SPIRIT-H2H [21] and EXCEED [22]). Moreover, in France, UST and SEK are subjected to hospital prescription. Thus, our study is representative of all PsA patients treated in France with these molecules. There was also an important number of centres (18) including 12 university hospitals from all over France involved in this study, increasing its external validity.

A limitation of this study was the presence of missing data in some covariates (Supplementary Table 1, available at Rheumatology online) included in the propensity score calculation. Although we used multiple imputations to handle missing data as appropriate, we could not exclude that missing data could introduce a bias in estimates. However, this large real-world cohort may allow propensity-score-based analysis and subgroup analysis. Only $60 \%$ of the patients with SEK were treated with the recommended dosage compared with the patients of the UST group (97\%), which could have impacted the persistence. SEK was prescribed at a lower dosage than recommended in the other patients. A possible reason could be that these patients received secukinumab in doses recommended for spondyloarthritis even if these patients were diagnosed with PsA. PsA is considered by some rheumatologists as part of the spectrum of spondyloarthritis. The dosing scheme of $150 \mathrm{mg}$ every 4 weeks is recommended for patients with axial spondyloarthritis. Another possible reason is economic. Secukinumab at $300 \mathrm{mg}$ every 4 weeks is more expensive than secukinumab at $150 \mathrm{mg}$ every 4 weeks (twice the price). In the basis of cost-effectiveness, some rheumatologists could have started with secukinumab at $150 \mathrm{mg}$ every 4 weeks, then increased to $300 \mathrm{mg}$ every 4 weeks. Yet, the persistence of SEK was still superior to the persistence of UST. In subgroup analysis, there was no difference in drug persistence between SEK and UST according to dosage (maximum or not).

Another limitation is the number of subgroup analysis as it was an exploratory study. There is still a risk that the 'Combination with MTX' subgroup reached a significant $P$-value by chance. However, the same results were obtained with two different methods (propensitymatched score method and IPTW score method).

In conclusion, SEK had a greater persistence than UST in PsA. In subgroup analysis, this difference was only found in association with MTX. UST had a numerically lower number of discontinuations due to an adverse event than SEK. This study could help the rheumatologist choose the most adequate bDMARDs for patients with PsA in everyday practice.

\section{Acknowledgements}

This work was previously presented at the 2020 EULAR congress in June 2020: FRI0348. See the meeting proceedings at Letarouilly JG, Flachaire B, Labadie C et al. FRI0348 Persistence of Secukinumab and Ustekinumab in Psoriatic Arthritis: A Real-Wolrd Multicentre Cohort of 409 Patients. EULAR 2020. Ann. Rheum. Dis. 2020; 79:769-769.

Funding: No specific funding was received from any funding bodies in the public, commercial or not-forprofit sectors to carry out the work described in this manuscript.

Disclosure statement: J.-G.L. reports a research grants from Pfizer, outside the submitted work. J.S. reports personal fees from MSD, Pfizer, Abbvie, Fresenius Kabi, BMS, Gilead, Novartis and Janssen (for advisory boards), Roche Chugai, Sandoz, Lilly (for symposia). P.R. reports consulting fees from AbbVie, Amgen, Biogen, BMS, Celgene, Janssen-Cilag, Lilly, Medac, MSD, NORDIC Pharma, Novartis, Pfizer, Roche, SanofiAventis, UCB. P.D. reports consulting fees from BMS, Pfizer, Roche-Chugai, Medac, Lilly, Sanofi-Genzyme, Janssen and research grants from BMS, Pfizer and Roche-Chugai. P.C. reports consulting fees from Abbvie, Pfizer, Roche-Chugai Bristol-Myers Squibb, MSD, UCB, Novartis, Janssen, Lilly, Celgene $(<\$ 10000$ each), and has been investigator for Roche Chugai, Sanofi Aventis, Celgene, Pfizer, MSD, Novartis and BMS. B.Fa. has received consultancy fees from AbbVie, Amgen, Biogen, BMS, Celgene, Janssen-Cilag, Lilly, Medac, MSD, Mylan, NORDIC Pharma, Novartis, Pfizer, Roche, Sanofi-Aventis, SOBI, UCB, and research grants from AbbVie, Lilly, MSD, Pfizer, Sanofi-Aventis. E.H. reports speaker's fees from Lilly, Pfizer, Novartis, Celgene, Sanofi and Roche Chugai. X.D. reports speaker's fees from Lilly and Novartis. J.-H.S. reports consulting fees from Novartis and Janssen. G.B. has received speaker's fees from BMS, Celgene, MSD, Nordic, Novartis, Pfizer and Roche-Chugai. C.M.-R. reports grants from Novartis and is member of the national advisory board of rheumatology of Novartis. E.G. reports grants from BMS, Abbvie, Roche-Chugai, Lilly, Novartis and Pfizer. I.C.-V. reports consulting fees from Abbvie, Bristol-Myers Squibb, Janssen, Lilly, MSD, Novartis, Pfizer, Roche, UCB. P.L. reports speaker's fees from Abbvie, Amgen, Biogaran, BMS, Expanscience, Lilly, Mylan, Pfizer, Roche-Chugai, UCB and fees from Abbvie, Amgen, BMS, Pfizer, UCB. P.P. reports speaker's fees from MSD, Abbvie, Jansen, Sanofi, Novartis, Amgen and has been investigator for MSD, Abbvie, Jansen, Sanofi, Novartis and Amgen. D.L. reports consulting fees from BMS and MSD. C.R. reports consulting fees from Abbvie, Amgen, Astra Zeneca, GSK, Janssen, Lilly, MSD, Mylan, Novartis, Pfizer and UCB and is the 
President of the Club Rhumatismes et Inflammation (CRI), which has recently received research funding and grants from Amgen, Sandoz, Sanofi, Lilly, Pfizer, MSD, Mylan, Novartis and UCB. F.T. is head of the Centre de Pharmacoépidémiologie (Cephepi) of the Assistance Publique - Hôpitaux de Paris and of the Clinical Research Unit of Pitié-Salpêtrière hospital, both these structures have received research funding, grants and fees for consultant activities from a large number of pharmaceutical companies, that have contributed indiscriminately to the salaries of its employees. F.T. did not receive any personal remuneration from these companies. T.P. reports consulting fees from Abbvie, Amgen, Biogen, BMS, Celgene, Fresenius-Kabi, Janssen, Lilly, Medac, MSD, Nordic, Novartis, Pfizer, Roche-Chugai, Sandoz, Sanofi and UCB. R.-M.F. is a member of the national advisory board of rheumatology/immunology of Janssen. He reports research grants from Janssen and Novartis. The other authors have declared no conflicts of interest.

\section{Data availability statement}

Data are available to check the quality of the article. They cannot be used for another study without requesting permission from the authors.

\section{References}

1 Gossec L, Baraliakos X, Kerschbaumer A et al. EULAR

recommendations for the management of psoriatic arthritis with pharmacological therapies: 2019 update. Ann Rheum Dis 2020;79:700-12.

2 Gossec L, Smolen JS, Ramiro S et al. European League Against Rheumatism (EULAR) recommendations for the management of psoriatic arthritis with pharmacological therapies: 2015 update. Ann Rheum Dis 2016;75: 499-510.

3 Harrold LR, Stolshek BS, Rebello S et al. Impact of prior biologic use on persistence of treatment in patients with psoriatic arthritis enrolled in the US Corrona registry. Clin Rheumatol 2017;36:895-901.

4 Lubrano E, Perrotta FM. Secukinumab for ankylosing spondylitis and psoriatic arthritis. Ther Clin Risk Manag 2016;12:1587-92.

5 Roberts J, O'Rielly DD, Rahman P. A review of ustekinumab in the treatment of psoriatic arthritis. Immunotherapy 2018;10:361-72.

6 Caso F, Del Puente A, Peluso R et al. Emerging drugs for psoriatic arthritis. Expert Opin Emerg Drugs 2016;21: 69-79.

7 Wendling D, Lukas C, Prati C et al. 2018 update of French Society for Rheumatology (SFR) recommendations about the everyday management of patients with spondyloarthritis. Jt Bone Spine 2018;85: 275-84.

8 Mclnnes IB, Kavanaugh A, Gottlieb AB et al. Efficacy and safety of ustekinumab in patients with active psoriatic arthritis: 1 year results of the phase 3 , multicentre, double-blind, placebo-controlled PSUMMIT 1 trial. Lancet 2013;382:780-9.

9 Mclnnes IB, Mease PJ, Kirkham B et al. Secukinumab, a human anti-interleukin-17A monoclonal antibody, in patients with psoriatic arthritis (FUTURE 2): a randomised, double-blind, placebo-controlled, phase 3 trial. Lancet 2015;386:1137-46.

10 Rothwell PM. External validity of randomised controlled trials: "to whom do the results of this trial apply?" Lancet 2005;365:82-93.

11 Kennedy-Martin T, Curtis S, Faries D, Robinson S, Johnston J. A literature review on the representativeness of randomized controlled trial samples and implications for the external validity of trial results. Trials 2015;16:495.

12 Queiro R, Coto-Segura P. Ustekinumab in psoriatic arthritis: need for studies from real-world evidence. Expert Opin Biol Ther 2018;18:931-5.

13 Queiro R, Brandy A, Rosado MC et al. Minimal disease activity and patient-acceptable symptom state in psoriatic arthritis: a real-world evidence study with ustekinumab. J Clin Rheumatol 2018;24:381-4.

14 Chimenti MS, Ortolan A, Lorenzin M et al. Effectiveness and safety of ustekinumab in naïve or TNF-inhibitors failure psoriatic arthritis patients: a 24-month prospective multicentric study. Clin Rheumatol 2018;37:397-405.

15 Almirall M, Rodriguez J, Mateo L, Carrascosa JM et al. Treatment with ustekinumab in a Spanish cohort of patients with psoriasis and psoriatic arthritis in daily clinical practice. Clin Rheumatol 2017;36:439-43.

16 Walsh JA, Adejoro O, Chastek B, Palmer JB, Hur P. Treatment patterns among patients with psoriatic arthritis treated with a biologic in the United States: descriptive analyses from an administrative claims database. J Manag Care Spec Pharm 2018;24:623-31.

17 lannone F, Santo L, Bucci R et al. Drug survival and effectiveness of ustekinumab in patients with psoriatic arthritis. Real-life data from the biologic Apulian registry (BIOPURE). Clin Rheumatol 2018;37:667-75.

18 Azuaga AB, Frade-Sosa B, Laiz A et al. Effectiveness of ustekinumab in patients with psoriatic arthritis in a realworld, multicenter study. Clin Rheumatol 2020;39: 2963-71.

19 Pinto Tasende JA, Maceiras Pan FJ, Mosquera Martínez JA et al. Secukinumab as biological treatment for psoriatic arthritis in real clinical practice. Reumatol. Clin 2019;S1699-258X(19)30112-3.

20 Mann HF, Závada J, Šenolt L et al. Real world use of secukinumab for treatment of axial spondyloarthritis and psoriatic arthritis: nationwide results from the ATTRA registry. Clin Exp Rheumatol 2019;37:342-3.

21 Mease PJ, Smolen JS, Behrens F, Nash P et al. A headto-head comparison of the efficacy and safety of ixekizumab and adalimumab in biological-naïve patients with active psoriatic arthritis: 24-week results of a 
randomised, open-label, blinded-assessor trial. Ann Rheum Dis 2020;79:123-31.

22 Mclnnes IB, Behrens F, Mease PJ et al. Secukinumab versus adalimumab for treatment of active psoriatic arthritis (EXCEED): a double-blind, parallel-group, randomised, active-controlled, phase $3 \mathrm{~b}$ trial. Lancet 2020; 395:1496-505.

23 Austin PC. Balance diagnostics for comparing the distribution of baseline covariates between treatment groups in propensity-score matched samples. Stat Med 2009;28:3083-107.

24 Austin PC. A comparison of 12 algorithms for matching on the propensity score. Stat Med 2014;33:1057-69.

25 Mattei A. Estimating and using propensity score in presence of missing background data: an application to assess the impact of childbearing on wellbeing. Stat Methods Appl 2009;18:257-73.

26 Toutenburg H, Rubin DB. Multiple imputation for nonresponse in survey. Stat Pap 1990;31:180.

27 Kirson NY, Rao S, Birnbaum HG et al. Matchingadjusted indirect comparison of adalimumab vs etanercept and infliximab for the treatment of psoriatic arthritis. J Med Econ 2013;16:479-89.
28 Mclnnes IB, Nash P, Ritchlin C et al. Secukinumab for psoriatic arthritis: comparative effectiveness versus licensed biologics/apremilast: a network meta-analysis. J Comp Eff Res 2018;7:1107-23.

29 Nash P, Mclnnes IB, Mease PJ et al. Secukinumab versus adalimumab for psoriatic arthritis: comparative effectiveness up to 48 weeks using a matchingadjusted indirect comparison. Rheumatol Ther 2018;5: 99-122.

30 Mease PJ, Collier DH, Saunders KC et al. Comparative effectiveness of biologic monotherapy versus combination therapy for patients with psoriatic arthritis: results from the Corrona registry. RMD Open 2015;1: e000181.

31 Fagerli KM, Lie E, van der Heijde $\mathrm{D}$ et al. The role of methotrexate co-medication in TNF-inhibitor treatment in patients with psoriatic arthritis: results from 440 patients included in the NOR-DMARD study. Ann Rheum Dis 2014;73:132-7.

32 Deodhar A, Gladman DD, Mclnnes IB et al. Secukinumab immunogenicity over 52 weeks in patients with psoriatic arthritis and ankylosing spondylitis. J Rheumatol 2020;47:539-47. 